\title{
Cogestão e Prevenção das DST/Aids na Atenção Primária: Contribuições desde o Referencial dos Direitos Humanos e da Vulnerabilidade
}

\author{
Dulce Aurélia de Souza Ferraz ${ }^{1}$ \\ Diretoria Regional de Brasília da Fundação Oswaldo Cruz, Brasília, Brasil \\ Maria Ines Battistella Nemes \\ Faculdade de Medicina da Universidade de São Paulo, São Paulo, Brasil
}

\begin{abstract}
Resumo
A implantação de ações de prevenção das DST/aids nos serviços de atenção primária à saúde é diretriz nacional e se coaduna com os princípios organizativos desse nível de atenção. Contudo, características da organização do trabalho em saúde predominante no Brasil associadas à baixa definição tecnológica dessas ações têm limitado sua efetivação conforme os princípios do quadro da vulnerabilidade e dos direitos humanos. Partindo da análise da reunião devolutiva de estudo sobre a implantação dessas ações numa Unidade de Saúde da Família, este artigo analisa as potencialidades dos espaços de cogestão para o aprimoramento desse processo de implantação, bem como do referencial da vulnerabilidade e dos direitos humanos, articulado à teoria do trabalho em saúde, para reorientação das práticas. Os resultados mostram que esses espaços, orientados pelos referenciais supracitados, favorecem o reconhecimento do processo de trabalho, a identificação das dificuldades vivenciadas pelos profissionais em relação à prevenção das DST/aids e contribuem para a formulação de soluções baseadas nas experiências concretas. Visando a avançar na implantação das ações, sugerem-se ações continuadas de cogestão e aproximação com experiências convergentes no âmbito do Sistema Único de Saúde.
\end{abstract}

Palavras-chave: Aids, atenção primária à saúde, vulnerabilidade, direitos humanos, cogestão.

\section{Co-Management and Prevention of STDIAIDS in Primary Care: Contributions from the Human Rights and Vulnerability Framework}

\begin{abstract}
The implementation of STD/AIDS prevention services in primary health care is a national recommendation, aligned with principles that organize that level of care in Brazil. However, characteristics of the predominant organization of health work in Brazil associated with low technological definition of these actions have limited its effectiveness according to the principles of the vulnerability and human rights framework. Based on the analysis of the return meeting of a study on the implementation of these actions in a Family Health Care Facility, this article examines the potential of co-management spaces
\end{abstract}

Endereço para correspondência: Fundação Oswaldo Cruz, Avenida L3 Norte, Campus Universitário Darcy Ribeiro, Gleba A, SC 4, Brasília, DF, Brasil 70910-900. E-mail: dulceferraz@fiocruz.br e mibnemes@usp.br Agradecemos à Professora Vera Paiva, por ter nos alertado para a riqueza do material produzido na reunião de devolutiva, contribuindo grandemente para a idealização deste texto; ao XII Programa de Introdução à Metodologia de Pesquisa em Gênero, Sexualidade e Saúde Reprodutiva, com base no qual o estudo original foi desenvolvido e por meio do qual foi financiado; à Professora Regina Maria Barbosa, pelas contribuições à elaboração e desenho do estudo original; e à Luzia Oliveira e Neide Kurokawa e Silva, pela cuidadosa e enriquecedora revisão do artigo.

Agência de Financiamento: Fundação Ford. 
for the improvement of this implementation process, as well as the potential of the vulnerability and human rights framework, articulated to the health work theory, to reorient prevention activities. Results show that these spaces, guided by the benchmarks above, leads to the recognition of the work process, the identification of the difficulties experienced by practitioners in relation to the prevention of STD/ AIDS and contribute to the formulation of solutions based on practical experience. Aiming to advance the implementation of actions, continued co-management actions are suggested as well as the approach with convergent experiments in the Brazilian health system.

Keywords: Aids, primary health care, vulnerability, human rights, co-management.

\section{Co-Gestión y Prevención de ETS/SIDA en Atención Primaria: Aportes desde el Marco de los Derechos Humanos y la Vulnerabilidad}

\section{Resumen}

La implantación de actividades de prevención de ITS/SIDA es una directiva nacional que está en consonancia con los principios de organización de este nivel de atención. Sin embargo, las características de la organización del trabajo en salud predominante en Brasil asociadas con la baja definición tecnológica de estas acciones se han limitado su efectuación de acuerdo con los principios del marco de la vulnerabilidad y los derechos humanos. A partir del análisis de la reunión devolutiva de una investigación sobre estas acciones en una Unidad de Salud de la Familia, este artículo examina el potencial de los espacios de co-gestión para la mejora de este proceso de implementación, así como analiza la potencia del marco de la vulnerabilidad y los derechos humanos, articulado a la teoría del trabajo en salud, para la reorientación de la prácticas. Los resultados muestran que estos espacios, guiados por los puntos de referencia anteriores, conducen al reconocimiento del proceso de trabajo, la identificación de las dificultades experimentadas por los profesionales relacionadas a la prevención de ITS/SIDA y contribuye para la formulación de soluciones basadas en la experiencia práctica. Con el objetivo de avanzar en la implementación de las acciones son sugeridas acciones continuadas de co-gestión y la aproximación a experiencias convergentes en el Sistema Brasilero de Salud.

Palabras clave: SIDA, atención primaria de salud, vulnerabilidad, derechos humanos, co-gestión.

... O Programa [de DST/Aids] não pode ser preconceituoso com a atenção básica. .

. Quem está visualizando que são necessárias inovações tecnológicas, o demandante, é que tem criar estratégia, tem que ampliar seu espaço. . . Tem que construir . . . tem que atuar na estrutura . . . E isso não é assim, "tem que ser devagar e sempre", não precisa nem ser devagar, tem que ser consistente e solidário (Coordenadora de Programa Municipal de DST/Aids²).

Em nossas reflexões sobre a implantação de ações de prevenção das DST/aids nos serviços

2 Os nomes da coordenadora e do município foram omitidos para preservar a identidade da informante. de Atenção Primária à Saúde (APS), temos sido instigadas e esclarecidas pelas palavras acima, ditas em entrevista pela coordenadora de um programa municipal de DST/Aids ao longo do estudo "Avaliação da Implantação das Ações de Prevenção das DST/Aids numa Unidade de Saúde da Família".

A frase instiga pelo desafio que enseja: que estratégias seriam essas a serem formuladas pelos Programas de DST/aids e que propiciariam as inovações tecnológicas desejadas? E esclarece pelas bases que indica: um trabalho na estrutura, consistente e solidário. Mas como operá-lo?

Trata-se de um desafio que não é exclusivo do campo das DST/aids. No processo de consolidação do Sistema Único de Saúde (SUS), a im- 
plantação das políticas em consonância com os princípios que o regem e as diretrizes específicas que as orientam é um processo complexo, que não pode ser reduzido à mera aplicação de técnicas, desconsiderando os sujeitos que as operam - os trabalhadores da saúde - e o contexto nos quais se inserem - os processos de trabalho vigentes nos serviços. As políticas, ao passarem do plano propositivo para o concreto, deixam de ser proposições para se transformarem em práticas sociais, submetendo-se às tensões intrínsecas ao cotidiano da vida social e do trabalho (Schraiber, 1997). Implantá-las demanda, então, ações de gestão que dialoguem com essas vicissitudes.

No caso específico das ações de prevenção das DST/aids em serviços de APS, em que pese haver diretrizes que as preconizem e investimentos para sua implantação desde meados dos anos 1990, os avanços tem sido restritos. Estudos empíricos realizados no Brasil e no mundo têm constatado a simplificação tecnológica das ações implantadas, com a redução do aconselhamento e das ações educativas ao repasse unilateral de informações e a priorização da implantação dos componentes tecnologicamente mais simples, como a disponibilização de preservativos e a realização de testes diagnósticos (Bellenzani, 2008; Caldwell \& Caldwell, 2002; Feliciano \& Kovacs, 2003; Ferraz, 2009; Ferraz \& Nemes, 2008; Fleishman-Foreit, Hardee, \& Agarwal, 2002). Distanciam-se, assim, da perspectiva da integralidade e do referencial da vulnerabilidade e dos direitos humanos que as orientam.

Apoiadas nos referenciais teóricos do trabalho em saúde (Mendes-Gonçalves, 1994) e do quadro teórico da vulnerabilidade e dos direitos humanos (Ayres, França, Calazans, \& Saletti, 2003; Paiva, 2002) e com base no estudo "Avaliação da Implantação das Ações de Prevenção das DST/aids numa Unidade de Saúde da Família" de nossa autoria, temos defendido a necessidade do aprimoramento das tecnologias de gestão para apoio aos serviços da APS no processo de implantação das ações de DST/aids (Ferraz, 2009; Ferraz \& Nemes, 2009, 2012).

Visando a contribuir com a proposição de caminhos para tanto, neste artigo analisamos a experiência da reunião devolutiva do referido estudo, buscando identificar nela: por um lado, as potencialidades de espaços democráticos de discussão e construção coletiva, identificados como espaços de cogestão (Mori \& Oliveira, 2009; Santos, Barros, \& Gomes, 2009), para a produção de práticas de saúde orientadas à integralidade e que objetivem os princípios orientadores da prevenção das DST/aids no Brasil; e, por outro, as potencialidades do quadro teórico da vulnerabilidade e dos direitos humanos como saberes mediadores (Ayres, 2009) desses encontros, favorecedores da formulação de soluções para os desafios vivenciados pelos profissionais de saúde no cotidiano de seu trabalho de prevenção das DST/aids.

Contextualizamos, inicialmente, as diretrizes de implantação e os principais achados de nosso estudo. Em seguida, apresentamos os procedimentos metodológicos de análise dos dados gerados a partir da reunião devolutiva para, em seguida, apresentar os resultados da análise. Finalizamos com considerações sobre as potencialidades dos espaços de discussão e construção coletiva e do quadro da vulnerabilidade e dos direitos humanos em contribuir com os objetivos da Estratégia de Saúde da Família (ESF) e da prevenção das DST/aids e apontamos experiências convergentes no âmbito do SUS que podem inspirar os avanços pretendidos.

\section{Avaliação da Implantação: Esmiuçando o Olhar Sobre as Práticas}

Desde meados dos anos noventa, realizar ações de prevenção das DST/Aids é uma atribuição que vem sendo conferida aos serviços de APS. Sinteticamente, as diretrizes oficiais do Ministério da Saúde preveem que esses serviços realizem: oferta de preservativos e de diagnóstico do HIV, da sífilis e das hepatites virais; assistência às pessoas com DST; orientações preventivas aos usuários nos atendimentos em geral; e atividades voltadas especificamente para inclusão dos segmentos populacionais mais vulneráveis ao HIV (Ministério da Saúde, 2006). São ações que devem ser guiadas pelo respeito aos direitos humanos, com abordagens voltadas para a redução das vulnerabilidades individual, social e programática e que considerem as dimensões 
subjetivas da prevenção e os contextos estruturantes da vida de indivíduos e coletividades (Ministério da Saúde, 2005).

No caso que estudamos, observamos, semelhantemente a outros estudos (Escorel, Giovanella, Mendonça, \& Senna, 2007; Schraiber, 2005), a persistência, no plano técnico-operativo da unidade de saúde da família (USF), da prioridade das atividades curativas, focadas no atendimento individual, embora com presença de algumas inovações tecnológicas indicativas das potencialidades da Estratégia de Saúde da Família para reversão desse quadro. Entendemos, com base no referencial teórico do trabalho em saúde (Mendes-Gonçalves, 1994), que essa persistência não reflete, meramente, a vontade individual dos profissionais que operam o cuidado na APS (Ayres, 2009). Ao contrário, elas compõem arranjos tecnológicos que, supervalorizando os saberes biomédicos, favorecem a fragmentação em lugar da integralidade e prejudicam a implantação de ações que se pautem em outros conjuntos de saberes, como é o caso das ações de prevenção das DST/aids no Brasil. Compreendendo os modelos de atenção à saúde como reflexos de um dado consenso sobre os modos de operar e gerir as tecnologias disponíveis e reconhecendo que tais tecnologias não são completamente moldáveis pelos modelos (Ayres, 2009), entendemos que esses limites não são inesperados, mesmo em serviços organizados por modelos de atenção à saúde orientados para a integralidade, como é a ESF. Isso porque a organização concreta do trabalho em saúde é sempre o resultado de um modo de articular as tecnologias, formulado pelos agentes do trabalho que, a partir dos saberes de que dispõem e das finalidades que almejam, recortam o objeto sobre o qual atuam e definem os instrumentos a serem utilizados nesse processo de transformação do objeto (Mendes-Gonçalves, 1994; Nemes, 2000). Portanto, haverá sempre um processo dialético entre a conformação das tecnologias ao modelo e o seu operar no cotidiano, o que demandará a renovação continuada dos arranjos tecnológicos, visando à conformação de novos modelos que se aproximem do horizonte prático que se quer alcançar - no caso da ESF, a integralidade da atenção (Ayres, 2009).

Inseridas nesse arranjo tecnológico, isto é, nesse modo de operar, o trabalho em saúde (Mendes-Gonçalves, 1994), identificamos que as ações de prevenção das DST/aids mais consistentemente implantadas foram aquelas com maior densidade tecnológica (Nemes, 2001) no plano normativo - ou seja, aquelas cujos modos de operar estavam mais claramente definidos em diretrizes e protocolos técnicos. Desse modo, compunham o trabalho da USF a oferta de testes diagnósticos e de preservativos masculinos, bem como a realização de orientações preventivas em alguns atendimentos individuais e coletivos e o tratamento de DST. Não obstante, essas ações caracterizavam-se pela simplificação técnica da abordagem, derivando daí o esvaziamento de sua função preventiva, especialmente a se considerar a dimensão comunicacional que as caracteriza. No que diz respeito ao diagnóstico, por exemplo, o aconselhamento (componente fundamentalmente preventivo da ação) com frequência deixava de ser realizado e, quando o era, restringia-se ao preenchimento de um formulário. A retirada de preservativos era permeada por uma série de obstáculos: requeria apresentação de documento de identificação na farmácia, tinha cotas fixas estabelecidas e não havia orientações sobre seu uso no momento da entrega. O tratamento das DST resumia-se à prescrição medicamentosa, sem esclarecimentos sobre formas de transmissão ou prevenção nem estabelecimento de mecanismos para tratamento de parceiros.

Além disso, identificamos que, mesmo considerando a prevenção o componente central do seu trabalho e relatando as orientações preventivas como parte importante dos atendimentos, na operação do trabalho os profissionais encontravam dificuldade em superar os modelos de prevenção normativos, caracterizados por abordagens genéricas e recomendações padronizadas. Quando, nos atendimentos, emergiam dificuldades de ordem subjetiva ou decorrentes do contexto social, econômico ou cultural dos usuários e da comunidade, aos profissionais faltavam instrumentos que lhes permitissem atuar de modo responsivo a essas necessidades. $\mathrm{O}$ mesmo se reproduzia em relação à discussão das dificuldades dos profissionais no exercício cotidiano de seu trabalho: com raros espaços de diálogo, suas dificuldades acabavam sendo subsumidas 
pelas atividades rotineiras do serviço e, quando emergiam numa eventual reunião, os instrumentos disponíveis eras insuficientes para superá-las (Ferraz, 2009; Ferraz \& Nemes, 2008, 2012).

É importante destacar que as ações de prevenção das DST/aids são altamente suscetíveis a variações contextuais (Cruz, Santos, \& Monteiro, 2007) não apenas em função da pouca densidade tecnológica que muitas vezes as caracteriza, mas também por sua alta complexidade assistencial, especialmente quando estão orientadas pelos referenciais do quadro teórico dos Direitos Humanos e da Vulnerabilidade. Ações de prevenção orientadas por esses referenciais partem do reconhecimento de que fatores sociais, culturais e políticos, geradores de desigualdades e de exclusão social, estão na base da suscetibilidade à infecção pelo HIV (Mann, Tarantola, \& Netter, 1993). Logo, não podem se restringir à modulação de comportamentos nem ao repasse de informações baseado em modelos cognitivistas de aprendizagem. Devem, ao invés, partir da análise do conjunto de interferências em cada situação, a fim de construírem sínteses compressivas que permitam um agir responsivo às necessidades de indivíduos ou comunidades frente ao HIV, a fim de se alcançar o que Ayres tem definido como sucesso prático (Ayres, 2009). Dialogando com a perspectiva construcionista sobre a sexualidade (Paiva, 2008), isso significa assumir um modo de operar as ações de saúde que reconhece como sujeitos todos os que nela estão envolvidos e que, portanto, deve se orientar pelos saberes que todos eles portam, sejam esses saberes derivados de sua formação técnico-científica, sejam oriundos das experiências cotidianas que conformam seus modos de existir no mundo, ou seja, sua sabedoria prática (Ayres, 2009).

De posse dessas reflexões, podemos afirmar que o avanço em direção à implantação de ações de prevenção na APS que objetivem os princípios do quadro dos Direitos Humanos e da Vulnerabilidade requer movimentos simultâneos de identificação e desenvolvimento de dispositivos tecnológicos que permitam viabilizar: de um lado, a reorientação do próprio modelo de atenção da APS em direção à integralidade; e, de outro, a operacionalização daquelas tecnologias de prevenção que, por suas características intrinse- camente comunicacionais, são menos passíveis de normatizações técnicas.

Para tanto, um caminho que nos parece particularmente fecundo é investir na ampliação e qualificação dos espaços de diálogo entre trabalhadores da gestão e da atenção baseados no fazer cotidiano dos serviços (Oliveira, Landroni, Silva, \& Ayres, 2005), buscando tecnologias que favoreçam a redução da vulnerabilidade programática, na medida em que, ao olhar para o processo, permitam aos profissionais de saúde ressignificar e reorientar o modo de operar o trabalho, ao mesmo tempo em que permitam aos gestores se aproximar do universo complexo que é o cotidiano dos serviços. Trata-se de um caminho que já vem sendo traçado em iniciativas variadas no âmbito do SUS, com dispositivos como o apoio institucional (Mori \& Oliveira, 2009; Santos et al., 2009) e o matriciamento (Cunha \& Campos, 2011), utilizados, por exemplo, na estruturação das redes temáticas de atenção (Rede Cegonha, Rede de Atenção Psicossocial), nas ações da Política Nacional de Humanização e na própria Política Nacional de Atenção Básica (PNAB; Ministério da Saúde, 2011).

É com a mirada orientada por esses achados e por essas reflexões que partiremos agora para análise da reunião devolutiva do estudo que vimos discutindo.

\section{Métodos}

À semelhança de Oliveira et al. (2005), o estudo da experiência da reunião devolutiva foi definido a posteriori e a produção dos dados aproxima-se de uma observação participante, tendo a autora principal participado ativamente do episódio estudado como apresentadora dos dados e mediadora do debate. Dois documentos apoiaram a análise: a síntese do estudo, entregue a todos os participantes da reunião; e o relatório da reunião de devolutiva, contendo a síntese das discussões realizadas.

À época do trabalho de campo, a unidade estudada era composta por uma equipe mínima de saúde da família. Os dados do estudo original foram obtidos por meio de observação direta de todas as atividades que compunham o processo de trabalho da USF e de entrevistas semidirigi- 
das com três ACS, um enfermeiro, um médico e duas auxiliares de enfermagem, todas realizadas pela pesquisadora principal, no período entre setembro e novembro de 2006 . A reunião aconteceu em junho de 2007 na própria Unidade de Saúde da Família estudada, com agendamento prévio de um mês. Foram convidadas, além dos membros da equipe da USF, as representantes da Coordenação Municipal de DST/Aids que participaram do estudo. Estiveram presentes: uma coordenadora do Programa Municipal de DST/Aids; três Agentes Comunitárias de Saúde (ACSs) e um enfermeiro que participaram da pesquisa; e três ACSs e uma enfermeira que se integraram à equipe após a realização do trabalho de campo. Os demais profissionais (dois médicos, dez ACS e quatro auxiliares de enfermagem) não participaram por estarem envolvidos em outras atividades de atendimento na USF.

Mantendo-se o rigor teórico da análise, porém, procurando descrever os achados e suas interpretações de modo inteligível para um público não habituado à linguagem científica, um resumo do estudo sistematizado num documento de 10 páginas foi entregue a toda equipe no dia da reunião. A fim de preservar o anonimato, nos casos relatados no documento foram omitidos nomes e categorias profissionais dos responsáveis pelos atendimentos transcritos. Esse cuidado tornou-se extremamente relevante para evitar a exposição dos profissionais, face à existência de muitos pontos frágeis a serem discutidos coletivamente.

O documento foi subdividido em:

1. Apresentação: explicitação dos objetivos da reunião de devolutiva.

2. Porque resolvemos fazer esta pesquisa: apresentação das diretrizes do Ministério da Saúde para a prevenção das DST/aids nos serviços de APS; evidências sobre as potencialidades e os desafios da implantação; motivos para a escolha da USF para estudo; perguntas do estudo, amparadas na teoria da organização do processo de trabalho em saúde.

3. O que encontramos: apresentação de resultados selecionados, representativos do conjunto dos dados analisados, divididos em duas categorias: perfil tecnológico da USF e perfil tecnológico das ações de prevenção. Este último foi subdividido em: ações integradas a atividades que já existiam na USF; atividades específicas de prevenção das DST/aids; atividades que não foram implantadas; atividades que deixaram de existir; atividades pontuais que já foram realizadas pela equipe.

4. Como a teoria nos ajuda a entender esses dados: análise dos dados selecionados, complementada com exemplos das observações realizadas no serviço.

5. Avanços e desafios: identificação das atividades de prevenção implantadas e das que ainda poderiam ser incorporadas; indicação de alternativas para a organização tecnológica do serviço visando à concretização de práticas que contribuiriam para a redução da vulnerabilidade da população atendida pelo serviço, de modo a torná-las mais coerentes com o plano ético-normativo do Programa Brasileiro de Aids e da Estratégia de Saúde da Família.

6. Agradecimentos.

7. Fluxograma da USF: representação gráfica do perfil tecnológico, com destaque para as ações de prevenção de DST/aids.

Coerentemente com os pressupostos da teoria da organização do trabalho em saúde, embora a ênfase estivesse nas ações de prevenção das DST/aids, a análise partiu do conjunto da organização do trabalho para, posteriormente, aproximar-se do recorte que nos interessava destacar.

Os dados foram debatidos pelos participantes da reunião por cerca de uma hora e meia e os principais pontos da discussão foram posteriormente sistematizados em relatório.

Para a produção deste artigo, os dados destes dois documentos foram analisados em conjunto e foram categorizados em cinco dimensões: as ações de prevenção das DST/aids no conjunto das finalidades do trabalho da APS; o processo de trabalho da equipe da USF; os objetivos das ações de prevenção e as práticas de saúde que as favorecem; a complexidade do trabalho realizado na APS; e a valorização dos trabalhadores como sujeitos do trabalho. Orientaram a análise de todas as dimensões os referenciais teóricos da organização do trabalho em saúde (Mendes- 
-Gonçalves, 1994) e o quadro da Vulnerabilidade e dos Direitos Humanos (Ayres et al., 2003; Paiva, 2002).

\section{Resultados}

\section{Das Finalidades do Trabalho: Por que Implantar Ações de Prevenção das DST/Aids na USF?}

É amplamente conhecida no Brasil a sobrecarga dos serviços de saúde. No caso da APS, um dos mecanismos de delimitação do trabalho é a definição, no plano normativo, de agravos e grupos populacionais prioritários a serem assistidos. À época da realização do estudo e ainda hoje, a atenção às DST e à aids não figurava entre essas prioridades (Ministério da Saúde, 2006, 2011). Entretanto, a prevenção de agravos, em geral, compõe a missão da ESF (Ministério da Saúde, 2011) e, além disso, atribui-se às equipes de saúde identificar, em sua área de atuação, as principais necessidades de saúde da população a que atendem e, a partir daí, redefinir suas prioridades (Ministério da Saúde, 2011).

Ocorre que, assoberbadas pela necessidade de responder às demandas, sobretudo as assistenciais, poucas vezes as equipes de saúde têm oportunidades para refletir sistematicamente sobre as demandas que emergem nos contatos cotidianos com a comunidade e, a partir delas, redefinir o processo de trabalho. Na prática, várias diretrizes programáticas vão sendo trazidas para o serviço, agregando-se como novas tarefas ou responsabilidades adicionais.

A discussão, baseada em informações epidemiológicas e em evidências científicas, sobre as razões para a APS ser considerada estratégica para a prevenção das DST/aids foi um momento de reflexões profícuas para a equipe. Todos ficaram interessados, por exemplo, em saber mais sobre os estudos de trajetórias de mulheres com HIV pelos serviços e seus diagnósticos tardios, porque reconheceram isso como algo bastante próximo da sua realidade: a dificuldade de identificar eventuais casos de aids ou mesmo de lidar com os casos de outras DST. Conforme os dados dessas pesquisas eram apresentados, os profissionais davam demonstrações de concordância com informações como: "as mulheres não se recordam de terem recebido informações sobre aids nos serviços"; "é comum que os profissionais só desconfiem que uma mulher está infectada quando o parceiro dela morre em decorrência da aids"; e "há dificuldade em se falar sobre sexualidade nos serviços de saúde". Indicavam, assim, perceber situações similares na sua prática profissional.

Com certa base de conhecimentos científicos e práticos compartilhados, abriu-se espaço para a reflexão seguinte, que era a de analisar a organização do processo de trabalho da unidade.

\section{Reconhecimento do Processo de Trabalho}

A discussão foi iniciada por uma apresentação sintética do quadro teórico que orientou o estudo, passando-se, a seguir, para a descrição das atividades da unidade. Como características relevantes da prioridade que assumem na totalidade do trabalho, foram indicadas: a frequência das atividades; o envolvimento da equipe na realização de cada uma delas; suas formas de agendamento; e sua suscetibilidade a cancelamentos e postergações.

Não foi difícil para a equipe perceber a centralidade da assistência individual "curativa" em seu trabalho: enquanto os atendimentos médicos eram agendados com antecedência, raramente cancelados e com o envolvimento de toda a equipe, ocupando a maior parte do seu tempo, as atividades essencialmente preventivas - grupos de planejamento familiar, de gestantes, aconselhamento - não contavam com calendário predefinido nem com espaço físico próprio, sendo frequentemente canceladas.

A partir daí, puderam refletir sobre as mudanças que haviam ocorrido desde a conclusão do trabalho de campo, resultantes, principalmente, da finalização do prédio da USF e do crescimento da equipe. Como agora havia uma sala de reuniões e dois enfermeiros na coordenação, fora possível estabelecer uma agenda de reuniões mensais da equipe e de reuniões semanais das ACSs com os enfermeiros. Com dois médicos na equipe, as visitas domiciliares desses profissionais puderam ser estendidas a outros usuários, além dos acamados. A melhoria do espaço físico trouxe também a possibilidade de fixar dias para 
os grupos de planejamento familiar e de papanicolau, reduzindo os cancelamentos.

Outra característica da organização do trabalho que dificultava a priorização de ações preventivas era a divisão iníqua das microáreas de atuação de cada ACS. A divisão inicialmente feita pela Secretaria Municipal de Saúde baseara-se fundamentalmente na geografia da área adstrita. A consequência era que as ACSs que atuavam nas áreas de habitação mais precárias (casas menores, com mais habitantes em cada uma, com piores condições de saneamento), onde eram esperadas maiores demandas, acompanhavam um número maior de famílias do que aquelas que atuavam nas áreas mais estruturadas do bairro. Com o aumento da equipe e da área adstrita, uma nova subdivisão foi feita, desta vez baseada no número de famílias acompanhadas, que passou a ser de aproximadamente 200 para cada ACS.

Em relação à organização das atividades de prevenção das DST/aids, a equipe informou manter-se a mesma da época do trabalho de campo e considerou fidedigna a descrição apresentada. A discussão seguinte, então, enfocou as características dessas ações, interessando aprofundar a análise sobre o modo como elas vinham sendo operacionalizadas pela equipe.

\section{Sujeitos de Direitos: Para Além do Éxito Técnico, a Autonomia e o Sucesso Prático como Horizontes Compartilhados}

A constatação de que as ações mais difíceis de serem implantadas são aquelas menos passíveis de serem padronizadas em protocolos e normas foi disparadora da reflexão sobre os modos de fazer prevenção, não só de DST/aids, mas de diversos agravos. A equipe reconheceu que o diálogo sobre prevenção de agravos estava reduzido ao repasse de informações genéricas aos usuários, como "precisa usar camisinha em todas as relações sexuais" (no caso da aids) e "não pode comer mocotó nem feijoada" (no caso da hipertensão). Daí em diante, pode refletir sobre as razões para terem adotado esse modelo em sua prática.

Primeiramente, reconheceram que a pouca clareza das diretrizes oficiais sobre como realizar uma abordagem de prevenção que extrapole esse modo de operar favorece que cada um atue da maneira que acredita ser a melhor, baseados em seus conhecimentos, experiências, crenças e julgamentos. Reinterpretaram, assim, o que diversos estudos já demonstraram: no Brasil, as fragilidades da formação de profi ssionais de saúde para lidar com as dimensões subjetivas (Tesser, 2009) e, especificamente, com a sexualidade, produzem práticas de saúde normalizadoras, reprodutoras do discurso sexológico disseminado no século XX, com forte viés moralizante e ancoradas em valores e noções pessoais (Paiva, 2008; Schraiber, 2005).

A equipe reiterou, porém, sua frustração com o limitado alcance dessas orientações. A partir disso, foram lançadas pela pesquisadora algumas reflexões baseadas na noção de vulnerabilidade sobre os possíveis motivos para os usuários não se comportarem exatamente do modo como "mandam" os protocolos e os serviços de saúde, a saber:

- Talvez as pessoas saibam que precisam usar o preservativo, mas não saibam como; talvez não consigam usá-lo porque não conseguem negociar isso com os parceiros ou porque têm vergonha de pedi-los nos serviços de saúde, onde tem de se identificar ou apresentar documentos; talvez não achem prazeroso adotar os hábitos que os serviços recomendam. De que maneiras o serviço poderia, então, identificar as razões ou dificuldades que impedem os usuários de se protegerem das DST/aids?

- Embora todos nós corramos o risco de nos infectar pelo HIV, as chances que temos de nos proteger são muito diferentes: porque somos mais ricos ou pobres, porque temos mais ou menos informação, porque interpretamos de maneira diferente as informações que ouvimos. Seria possível, então, abordar a todos da mesma maneira e esperar de todos respostas uniformes?

- Que resultados se podem esperar ao dizer a um homem ou uma mulher que depende economicamente de seu parceiro que ele ou ela tem que exigir o uso do preservativo? Ou que uma mulher deve recusar relações sexuais quando está fazendo tratamento de DST, sem dialogar com ela sobre as rela- 
ções em que está envolvida? Ou, ainda, que essa mulher deve obrigar seu parceiro a tratar-se? Em que o serviço de saúde contribui para a preservação da saúde de uma pessoa quando reduz sua ação ao dizer que ela tem que usar preservativo em todas as relações sexuais ou ao entregar-lhe medicamentos para tratamento de DST e dizer que ela vai ter que convencer o parceiro a se tratar?

Provocado por essas considerações, o grupo partiu para a identificação de outras maneiras de se fazer a prevenção. O que significaria, na prática, considerar os contextos de vulnerabilidade e respeitar os usuários como sujeitos de direitos - pessoas que têm direito à saúde, à autonomia, à vivência da sua sexualidade, sem discriminações (Paiva, 2008)?

Uma das ACSs disse que às vezes era preciso "ver o que cada um consegue fazer" e deu como exemplo duas situações: a primeira referia-se aos hábitos alimentares de sua avó hipertensa e habituada a comer carne seca diariamente. Como sabia que era impossível que a avó deixasse de comer a iguaria, a ACS negociara com ela que o fizesse menos vezes por semana. $\mathrm{O}$ grupo achou graça da situação, mas concordou que a medida mais viável para o caso era a negociação.

A segunda situação relatada foi a de uma usuária do serviço que sabia que seu companheiro tinha relações sexuais extraconjugais, mas que já relatara à ACS não ter coragem de pedir a ele que usasse o preservativo porque temia ser agredida fisicamente. A ACS estava profundamente angustiada com a situação, sem saber como agir, inclusive pelo temor de abordar mais insistentemente $o$ assunto e ser agredida pelo companheiro da usuária. $\mathrm{O}$ caso mobilizou a equipe que, diante de uma situação identificada por todos como complexa e angustiante, formulou uma solução: investigar com a usuária se ela desejava manter-se nessa relação e, caso não o desejasse, se necessitava de ajuda ou proteção para findá-la. Sendo este o caso, sugeriu-se que fosse demandada a ajuda da Coordenação Municipal de DST/Aids para abordar essa mulher com auxílio da equipe de prevenção e, posteriormente, que fossem articulados os demais parceiros, principalmente a Delegacia da Mulher e o Centro de Referência de Assistência Social.
Os exemplos permitiram aos profissionais concluir que as ações de prevenção poderiam ser mais efetivas se eles pudessem ouvir mais os usuários e suas dificuldades e, consequentemente, pudessem adequar as orientações preventivas à realidade de cada um, inclusive no que diz respeito à linguagem, e abrindo mão das prescrições. Sintetizado na afirmação textual de que "cada caso é um caso", o consenso do grupo foi de que era preciso negociar com cada usuário a melhor solução possível e compreender que nem todos terão condições ou mesmo desejo de seguir à risca as orientações ideais preconizadas nas diretrizes. Aproximavam-se, assim, da conclusão de que a o êxito técnico de suas ações só seria alcançável quando se configurasse, simultaneamente, como um sucesso prático na vida dos usuários, respeitando o direito de cada sujeito, autonomamente, identificar o mais conveniente para a sua vida (Ayres, 2009).

Como forma de dar mais concretude a essa conclusão, foi proposta pela pesquisadora uma reflexão sobre o aconselhamento pré-teste. Considerada uma tecnologia com grande potencial para a prevenção, já que a busca da testagem costuma ser indicativa de alguma percepção de risco por parte do sujeito que a demanda, poderia ser aproveitada pela equipe como uma oportunidade de conversar sobre questões que permitissem construir, conjuntamente, uma compreensão acerca da prevenção na vida do usuário: suas parcerias sexuais, seus modos de se prevenir, os métodos contraceptivos que usa, as percepções sobre as possibilidades de inclusão do preservativo nas suas relações, seu histórico de DST, seus hábitos de uso de drogas, seus conhecimento sobre riscos desse uso e as maneiras de evitá-los. No caso das gestantes, a noção de sujeito de direitos se mostrou mais desafiadora para a equipe. A pesquisadora lembrou ao grupo que, embora a testagem esteja prevista no protocolo do pré-natal, a diretriz preconiza a oferta deste procedimento acompanhada do aconselhamento, o que dá à gestante o direito, de posse das informações sobre a finalidade do teste, de decidir se irá realizá-lo ou não. Ao solicitar o anti-HIV sem consentimento da gestante, o profissional de saúde estaria, portanto, violando o direito da mulher de decidir autonomamente sobre como 
cuidar da própria saúde e da de seu filho. Para alguns profissionais, permaneceram algumas tensões em relação a esse direito, sob alegação da importância do cuidado com a saúde do bebê. Sem a pretensão de esgotar o tema, debateu-se, então, a importância do aconselhamento como uma oportunidade de avaliação conjunta dos riscos a que a mulher e o bebê estão expostos e das possibilidades de prevenção de que ela dispõe, buscando prestar os esclarecimentos que ela necessite e acolhendo suas reações e decisões.

\section{Da Complexidade do Cotidiano: Articular Saberes e Tecnologias para Aprimorar Práticas}

A emergência de situações que escapam à delimitação dos protocolos oficiais é um dos maiores desafios a serem superados no trabalho de prevenção das DST/aids. Nesse sentido, um exemplo trazido à tona pela discussão do estudo foi particularmente rico. Tratava-se de uma profissional do sexo atendida no serviço, que estava grávida pela quinta vez, e que, segundo a equipe, recorreria, também pela quinta vez, a um aborto. Era visível e manifesto o incômodo de todos com a situação, agravado, em alguns, também pela reprovação moral da prostituição e da possibilidade de interrupção voluntária da gravidez.

No intento de identificar como o serviço poderia contribuir para evitar a repetição desses ciclos de gestações e abortamentos inseguros, foram discutidas as opções contraceptivas da usuária. Segundo a equipe, ela relatava usar o preservativo, mas as gestações evidenciavam que estava havendo falhas nesse uso. $\mathrm{O}$ anticoncepcional injetável ou quaisquer outros métodos hormonais foram descartados pela usuária já que, segundo a equipe, ela temia que que a fizessem engordar. A sugestão do uso do DIU feita pela pesquisadora causou indignação, principalmente na enfermeira, que alegou que as múltiplas parcerias sexuais seriam contraindicativas do método. A situação causou bastante desconforto na equipe ao trazer à tona o conflito entre os valores pessoais, as normativas técnicas e os direitos reprodutivos da usuária. Seguindo na problematização, a pesquisadora questionou se esse não era a um caso a ser tratado como exceção - diante da situação, o que era preferível: seguir fielmente as recomendações previstas nos protocolos oficiais ou considerar as especificidades do caso, tentando reduzir os danos que a usuária vem sofrendo com as gestações e os abortos reincidentes? A enfermeira contra-argumentou, dizendo que nenhum médico colocaria DIU numa situação dessas. Os demais membros da equipe concluíram que era preciso negociar uma alternativa com a usuária, mas não conseguiram indicar uma solução para o caso. Relataram, contudo, depararem-se frequentemente com situações similares, com profissionais do sexo que adotam práticas arriscadas para a produção de infecções, como o uso de tampões de algodão na vagina para impedir a saída da menstruação, e que tem dificuldade em dialogar com elas sobre essas práticas.

$\mathrm{O}$ caso permitiu ao grupo perceber o quão complexo é o trabalho que se realiza na APS, ao mostrar que a inter-relação de aspectos sociais, culturais e subjetivos, além dos biológicos, interfere nas possibilidades de cuidado de cada pessoa. Ademais, evidenciou que esses modos de cuidar-se não se limitam a decisões puramente racionais, baseadas em informações científicas. Os usuários são sujeitos e sua história, suas relações, seu contexto de existência precisam de espaço para emergir nas práticas de saúde, a fim de que as informações científicas que embasam os protocolos oficiais sejam ressignificadas, dialogando com os projetos de felicidade (Ayres, 2009) que orientam a "vida real" das pessoas. O caso confrontou a equipe, uma vez mais, com o desafio de escapar às restrições de viéses moralistas ou tecnicistas para reorientar o olhar pelo referencial dos direitos humanos, ao questionar: como traduzir direitos universais - no caso, os sexuais e reprodutivos - em condutas e terapêuticas que respondam às necessidades de cada caso?

Perceber a magnitude desta tarefa pode ser paralisante para as equipes de saúde (Oliveira et al., 2005). Por essa razão, foi importante a continuação da discussão, esclarecendo que nem todas as soluções poderão ser encontradas individualmente por cada profissional e, algumas delas, nem mesmo na atuação da equipe da USF. As transformações das práticas somente se tornariam possíveis quando fossem feitas altera- 
ções na organização do processo de trabalho. Por exemplo, o encaminhamento de casos como o da usuária vítima de violência às equipes de prevenção do Programa Municipal de DST/Aids dependeria da criação de mecanismos de referência e contrarreferência até então inexistentes; mudanças na prática do aconselhamento necessitariam ser planejadas, com a definição dos profissionais responsáveis, a identificação da melhor forma de organizar a oferta, com base nas necessidades da comunidade, nas especificidades desse tipo de ação e nas possibilidades do serviço; e assim por diante.

Nesse sentido, foi particularmente enriquecedora a presença da coordenadora municipal de DST/Aids na reunião, que permitiu o comprometimento do Programa com a busca de soluções para os casos que extrapolam a capacidade de ação da APS. Isso reforçou a percepção do grupo, inclusive da própria coordenadora, sobre a importância de se fortalecerem alguns mecanismos de atuação conjunta, como supervisões em serviço, reuniões entre equipes e capacitações específicas. As ACSs reivindicaram a organização de um dia de trabalho conjunto entre a equipe da USF e as equipes de DST/Aids do município, alegando que isso poderia lhes permitir conhecer melhor o modo como as equipes operacionalizam as atividades de prevenção e, ao mesmo tempo, ajudar-lhes a se aproximar de grupos específicos, como profissionais do sexo, travestis e pessoas que vivem com HIV.

\section{Sujeitos de Direitos II: Os Profissionais de Saúde, seus Saberes e suas Potencialidades}

Se é preciso, por um lado, reconhecer que as práticas dos serviços muitas vezes reduzem os usuários a receptores de informações, cujos comportamentos devem ser moldados conforme recomendações gerais, desconsiderando sua história e seu contexto de vida, por outro é preciso admitir que, em tantas outras vezes, o mesmo é feito em relação aos trabalhadores de saúde.

Com currículos extremamente focados (quando não restritos) aos conhecimentos de base biomédica, tendo como lócus de aprendizagem prioritário o hospital (Tesser, 2006, 2009) a formação oficial dá início a uma série de intervenções educacionais às quais serão submetidos os profissionais de saúde. Atuando nos serviços, serão inúmeras as capacitações, atualizações, sensibilizações, sobre os mais diversos temas, a depender das prioridades estabelecidas no âmbito da gestão.

A oferta dessas atividades, em si, é meritória, assim como são louváveis os esforços de integrá-las e aprimorá-las, expressos na Política de Atenção Básica (Ministério da Saúde, 2011). Porém, é importante refletir sobre o modo como essas formações vêm sendo conduzidas e sobre as limitações desse tipo de estratégia para a implantação de políticas e ações que traduzam o referencial dos direitos humanos e o princípio da integralidade.

Os profissionais da USF que estudamos relataram ter passado por um conjunto de atividades de formação para atuação na ESF e, posteriormente, em maior ou menor quantidade, de outras atividades de capacitação sobre temas específicos, afeitos às atribuições da APS. Passavam, periodicamente, por supervisões técnicas da equipe como um todo e de segmentos específicos, sendo algumas direcionadas a atividades também específicas, inclusive as de prevenção de DST/aids. No plano discursivo, estavam imbuídos do espírito transformador da ESF, de seus ideais preventivos e participativos. Reconheciam as ações de prevenção das DST/aids como uma necessidade da comunidade à qual deveriam atender, ofertando insumos, orientações, testagem, enfim, garantindo direitos. Não encontravam, porém, instrumentos para concretizar esse ideário naquela que era sua realidade concreta: a de profissionais de saúde inseridos num serviço da periferia da região metropolitana de São Paulo, cuja organização tecnológica ainda estava centrada na viabilização do atendimento médico, individual e curativo.

Ao longo do trabalho de campo, já havíamos identificado o potencial da equipe em encontrar soluções para os desafios do trabalho quando havia oportunidade de espaços organizados para a reflexão coletiva. Na única reunião de equipe realizada nos três meses de observação do serviço, embora a prioridade tenha sido a discussão 
de questões administrativas, duas mudanças com potencial de impacto positivo no trabalho e na atenção à comunidade foram acordadas. A primeira foi a decisão de passar a agendar os atendimentos de crianças para o mesmo período, baseada na percepção da equipe de que muitas das mulheres tinham dificuldades em se adaptar à organização anterior, que separava os atendimentos das crianças em blocos de 02 a 05 anos e de 06 a 10 anos. A outra reivindicação importante que mereceu encaminhamento durante a reunião foi a queixa das ACSs de que nem todos os usuários que necessitavam de atendimento médico domiciliar o estavam recebendo, já que as visitas do médico estavam restritas aos usuários acamados. A equipe decidiu que as ACSs passariam a construir conjuntamente a agenda de visitas domiciliares do médico para cada microárea, com o objetivo de cobrir todas elas, e identificando os usuários que necessitavam, independentemente de estarem acamados ou não. Além disso, a presença da pesquisadora na reunião chamou a atenção da equipe para a temática das DST/aids. Após a reunião, uma série de materiais informativos que estavam guardados na USF foi colocada à disposição da comunidade: cartazes de estímulo à testagem foram afixados nas paredes e portas e folhetos informativos foram colocados sobre o balcão da recepção para serem retirados pela comunidade.

No caso da reunião devolutiva, por estar orientada para a reflexão sobre e a partir do processo de trabalho, trouxe aos profissionais uma oportunidade de reflexão que raramente acontecia na USF. O debate baseado na realidade do serviço e orientado por quadros teóricos que valorizam as singularidades da concretude do trabalho vivenciada pelos participantes foi disparador de um processo de reflexão extremamente rico. A equipe mostrou-se muito aberta ao diálogo, entendendo que os pontos frágeis apontados tinham como objetivo permitir-lhes compreender uma possibilidade de análise dos dados coletados e promover a reflexão acerca da criação de alternativas de melhoria. As críticas foram debatidas com muita seriedade e comprometimento da equipe. Tendo os referenciais teóricos como instrumentos, os profissionais identificaram casos desafiadores baseados nas suas vivências e no conhecimento que tem sobre a comunidade e, para alguns deles, formularam soluções concretas, também amparadas nesse diálogo entre os saberes científicos e seus saberes práticos. Outros casos permaneceram sem solução, indicando que a superação das práticas normatizadoras e tecnicamente simplificadas em prol de outras orientadas pelos direitos humanos é um processo que requer oportunidades de reflexão e reconstrução continuados.

\section{À Guisa de Concluir}

A necessidade de ampliar a cobertura das ações de prevenção das DST/aids e, para tanto, de articular diferentes atores na sua consecução, tem suscitado importantes debates sobre como operacionalizar o referencial do quadro da vulnerabilidade e dos direitos humanos. Incitados por esse desafio e estimulados pelo compromisso de fazer avançar a prevenção, pesquisadores, gestores e profissionais de saúde que atuam na prestação direta de serviços à população tem se empenhado para desenvolver recursos, tecnologias e dispositivos que favoreçam a concretização de práticas de saúde efetivamente orientadas para a redução das vulnerabilidades. Exemplos disso são os trabalhos de análise das cenas sexuais (Bellenzani, 2008; Paiva, 2006, 2008), as propostas de construção de matrizes de vulnerabilidade para orientação da ação nos municípios (Westin et al., 2009) e a organização de espaços de reflexão sobre as práticas dos serviços (Oliveira et al., 2005), apenas para citar alguns.

Nessa busca de caminhos, nos parece imprescindível reduzir a distância entre os que formulam e os que implantam a política de prevenção, assumindo, a exemplo do que propõe a Política de Humanização do SUS (Ministério da Saúde, 2006), o caráter de indissociabilidade das práticas de gestão e atenção. Em outras palavras, trata-se de adotar a cogestão (Mori \& Oliveira, 2009; Santos et al., 2009), valorizando os profissionais de saúde que atuam nos serviços de APS como sujeitos de suas práticas, corresponsáveis pela construção coletiva de soluções para os problemas que vivenciam e que, em grande parte, só poderão ser enfrentados pelo trabalho coletivo - de uma equipe ou de uma rede. Como vimos 
no exemplo analisado, as atividades coletivas reuniões, supervisões, capacitações - ganham quando se abrem para a manifestação dos sujeitos, com suas histórias, seus saberes, seus medos e suas potencialidades. Dito de outro modo, ganham quando se tornam espaços reflexivos e democráticos, onde aos vários sujeitos que vivem o serviço é concedido o direito à voz e onde os saberes que portam são valorizados, respeitados e empregados na construção de soluções.

Nessa perspectiva, assim como aos profissionais de saúde cabe serem mediadores do encontro entre os "sujeitos usuários dos serviços" e o conjunto de recursos necessários para alcançarem a saúde que almejam, aos gestores dos programas e gerentes dos serviços lhes cabe mediar o encontro entre os "sujeitos profissionais de saúde" e os instrumentos necessários para a consecução de práticas de saúde que objetivem os princípios éticos que as orientam: a integralidade da atenção, a redução das vulnerabilidades, a efetivação dos Direitos Humanos.

Um dispositivo que nos parece profícuo nesse processo de mediação é o apoio institucional, na medida em que propõe uma ação de acompanhamento qualificado do trabalho das equipes de saúde articulado à oferta de estratégias metodológicas para implementação de políticas (Mori \& Oliveira, 2009). Nesse processo de qualificação das políticas públicas de saúde, também as instituições de pesquisa e ensino podem contribuir, não apenas por meio da produção de conhecimento e da formação de profissionais, mas com atividades de extensão de apoio à gestão, à semelhança da experiência que relatamos.

No que tange à potência do quadro teórico da vulnerabilidade e dos direitos humanos como reorientador dos modos de operar as práticas de saúde, está claro que, por características próprias aos saberes que o fundamentam, o quadro não oferece modelos definitivos. Em nossa reunião, princípios importantes do quadro foram ricamente interpretados pelos profissionais de saúde ao serem remetidos à realidade das experiências que vivenciam no cotidiano da atenção. $\mathrm{O}$ reconhecimento dos usuários dos serviços como sujeitos da própria saúde, portadores de saberes e inseridos num contexto social, cultural e econômico está presente nas conclusões do grupo de que "cada caso é um caso", bem como nos momentos em que definem que a negociação é a melhor estratégia para alcançar o melhor resultado possível - o sucesso prático da ação - e até mesmo nos momentos em que as tensões não conseguem ser resolvidas pelo grupo em razão de sua complexidade. Nestas situações, em particular, a articulação do quadro com a teoria do processo de trabalho foi fundamental para impedir o imobilismo que, muitas vezes, pode ser produzido diante da constatação do grupo da impossibilidade de dar conta, isoladamente, de complexas tarefas. Baseados nas necessidades que perceberam em seu cotidiano, os profissionais puderam, por exemplo, demandar novas formas de atuação articuladas com equipes de outros serviços e programas e ressignificar momentos comumente desvalorizados no processo de trabalho, como é o caso das reuniões e supervisões de equipe.

De maneira sintética, o que observamos foi uma importante potencialidade desses referenciais de favorecerem a reflexão, a troca e a coconstrução de soluções para problemas cotidianos que, quando permanecem irresolutos, são geradores de angústia e frustração para os profissionais. Com o aporte compreensivo que oferecem, eles contribuem para a redefinição da finalidade do trabalho em saúde, relacionando os objetivos técnicos almejados pelos serviços com o sucesso prático de usuários e comunidade (Oliveira et al., 2005) e favorecendo um caminhar em direção à integralidade. Há que se ressalvar, ainda, que nesta experiência não exploramos a plenitude dos recursos que do quadro têm derivado, caso, por exemplo, da análise das cenas sexuais (Paiva, 2007, 2008) que poderiam ser propiciadoras de importantes inflexões no modo de compreender e realizar as ações de prevenção.

A considerar a riqueza da vida cotidiana, com seus múltiplos movimentos, é simples prever que os desafios da práxis serão sempre renovados e exigirão permanente busca de novas soluções. Temas complexos não encontram soluções imediatas nem simples. Do mesmo modo, cenários, cenas e atores se renovam amiúde, fazendo com que as soluções para organização das práticas não sejam definitivas. A continuidade é, portanto, característica fundamental para que es- 
ses espaços surtam os efeitos desejados e constituam-se, efetivamente, em espaços de construção consistentes e solidários, a partir dos quais novos modos de atuar, consonantes com os direitos humanos universais, possam ser efetivados.

\section{Referências}

Ayres, J. R. C. M. (2009). Organização das ações de atenção à saúde: Modelos e práticas. Saúde e Sociedade, 18(2), 11-23.

Ayres, J. R. C. M., França, I., Jr., Calazans, G. J., \& Saletti, H. C., Filho. (2003). O conceito de vulnerabilidade e as práticas de saúde pública: Perspectivas e desafios. In D. Czeresnia, \& C. M. Freitas (Orgs.), Promoção da saúde: Conceitos, reflexões, tendências (pp. 117-139). Rio de Janeiro, RJ: Fundação Oswaldo Cruz.

Bellenzani, R. (2008). Sexualidade entre jovens das comunidades anfitriãs de turismo: Desafios para a prevenção das DST/HIV e o Programa Saúde da Família (Dissertação de mestrado, Instituto de Psicologia, Universidade de São Paulo, SP, Brasil).

Caldwell, J. C., \& Caldwell, P. (2002). Is integration the answer for Africa? International Family Planning Perspectives, 28(2), 108-110.

Cruz, M. M., Santos, E. M., \& Monteiro, S. (2007). Evaluation of STD/AIDS prevention programs: A review of approaches and methodologies. $\mathrm{Ca}$ dernos de Saúde Pública, 23(5), 995-1003.

Cunha, G. T., \& Campos, G. W. S. (2011, out./dez.). Apoio matricial e atenção primária em saúde. Saúde e Sociedade, 20(4), 961-970.

Escorel, S., Giovanella, L., Mendonça, M. H. M., \& Senna, M. C. M. (2007). O Programa de Saúde da Família e a construção de um novo modelo para a atenção básica no Brasil. Revista Panamericana de Salud Pública, 21(2), 164-176.

Feliciano, K. V. O., \& Kovacs, M. H. (2003). As necessidades comunicacionais das práticas educativas na prevenção da transmissão materno-fetal do HIV. Revista Brasileira de Saúde Materno-Infantil, 3(4), 393-400.

Ferraz, D. A. S. (2009). Avaliação da implantação de ações de prevenção das DST/AIDS numa unidade de saúde da família (Dissertação de mestrado, Faculdade de Medicina, Universidade de São Paulo, SP, Brasil).
Ferraz, D. A. S., \& Nemes, M. I. B. (2008). Avaliação da implantação de atividades de prevenção das DST/AIDS na atenção básica: Um estudo de caso na Região Metropolitana de São Paulo, Brasil. Cadernos de Saúde Pública, 25(2), 240-250.

Ferraz, D. A. S., \& Nemes, M. I. B. (2012). Prevenção das DST e AIDS na atenção primária a saúde: Reflexões sobre as práticas a partir do estudo de uma Unidade de Saúde da Família. In V. Paiva, J. R. C. M. Ayres, \& L. Pupo (Orgs.), Direitos humanos e vulnerabilidade na prevenção e promoção da saúde - Livro I: Da doença à cidadania. Curitiba, PR: Juruá.

Fleishman-Foreit, K. G., Hardee, K., \& Agarwal, K. (2002). When does it make sense to consider integrating STI and HIV services with family planning services? International Family Planning Perspectives, 28(2), 105-107.

Mann, J., Tarantola, D. J. M., \& Netter, T.W. (Orgs.). (1993). A aids no mundo. Rio de Janeiro, RJ: Relume Dumará.

Mendes-Gonçalves, R. B. (1994). Tecnologia e organização social das práticas de saúde: Características tecnológicas de processo de trabalho na rede estadual de centros de saúde de São Paulo. São Paulo, SP: Hucitec.

Ministério da Saúde. (2005). Plano Estratégico do Programa Nacional de DST/AIDS. Brasília, DF: Autor. Recuperado em 24 de outubro de 2006, de http://bvsms.saude.gov.br/bvs/publicacoes/ plano_estrategico.pdf

Ministério da Saúde. (Org.). (2006). HIV/AIDS, hepatites e outras DST. Cadernos de Atenção Básica, 18.

Ministério da Saúde. (2011). Portaria $\mathrm{n}^{\circ}$ 2.488, de 21 de outubro de 2011. Aprova a Política Nacional de Atenção Básica, estabelecendo a revisão de diretrizes e normas para a organização da Atenção Básica, para a Estratégia Saúde da Família (ESF) e o Programa de Agentes Comunitários de Saúde (PACS). Diário Oficial da União, 204, Seção 1, p. 48.

Mori, M. E., \& Oliveira, O. V. M. (2009). Os coletivos da Política Nacional de Humanização (PNH): A cogestão em ato. Interface - Comunicação, Saúde, Educação, 13(Supl. 1), 627-640.

Nemes, M. I. B. (2000). Prática programática em saúde. In L. B. Schraiber, M. I. B. Nemes, \& R. B. Mendes-Gonçalves (Orgs.), Saúde do adulto: Programas e ações na unidade básica (2. ed., pp. 48-65). São Paulo, SP: Hucitec. 
Nemes, M. I. B. (2001). Avaliação em Saúde: Questões para os programas de DST/aids no Brasil: Vol. 1. Fundamentos de Avaliação. Rio de Janeiro, RJ: Associação Brasileira Interdisciplinar de AIDS.

Oliveira, L. A., Landroni, M. A. S., Silva, N. E. K., \& Ayres, J. R. C. M. (2005). Humanização e cuidado: A experiência da equipe de um serviço de DST/AIDS no município de São Paulo. Ciência \& Saúde Coletiva, 10(3), 689-698.

Paiva, V. (2002). Sem mágicas soluções: A prevenção do HIV e da AIDS como um processo de emancipação psicossocial. Interface - Comunição, Saúde, Educação, 6(11), 25-38.

Paiva, V. (2006). Analisando cenas e sexualidades: A promoção da saúde na perspectiva dos Direitos Humanos. In C. F. Cáceres C, M. Pecheny, T. Frasca, \& G. Careaga (Orgs.), Sexualidad, estigma y derechos humanos: desafios para el acceso a la salud en América Latina (pp. 23-52). Lima, Peru: Facultad de Salud Pública y Administración Carlos Vidal Layseca, Universidad Peruana Cayetano Heredia.

Paiva, V. (2007). Prevenção positHIVa: Abordagem psicossocial, emancipação e vulnerabilidade. Trabalho apresentado no Seminário Prevenção Posithiva: Estado da Arte, Rio de Janeiro, RJ, Brasil.

Paiva, V. (2008, out./dez.). A psicologia redescobrirá a sexualidade? Dossiê: Psicologia e sexualidade no século XXI. Psicologia em Estudo, 13(4), 641-651.

Santos, S. F., Filho, Barros, M. E. B., \& Gomes, R. S. (2009). A Política Nacional de Humanização como política que se faz no processo de trabalho em saúde. Interface - Comunição, Saúde, Educação, 13(Supl. 1), S603-S613.
Schraiber, L. B. (1997). Prefácio. In Z. M. A. Hartz (Org.), Avaliação em saúde: Dos modelos conceituais à prática na análise da implantação de programas. Rio de Janeiro, RJ: Fundação Oswaldo Cruz.

Schraiber, L. B. (2005). Equidade de gênero e saúde: O cotidiano das práticas no Programa de Saúde da Família do Recife. In W. Villela, \& S. Monteiro (Orgs.), Gênero e saúde: Programa de Saúde da Família em questão (pp. 39-61). Rio de Janeiro, RJ: Associação Brasileira de Saúde Coletiva.

Tesser, C. D. (2006). Medicalização social (II): Limites biomédicos e propostas para a clínica na atenção básica. Interface - Comunicação, Saúde, Educação, 10(20), 347-362.

Tesser, C. D. (2009). Três considerações sobre a "má medicina”. Interface - Comunicação, Saúde, Educação, 13(31), 273-286.

Westin, C., Giovanetti, M., Yamaçake, A., Campos, L. C., Pereira, M. L., \& Filipe, E., (2009). Revisitando e ampliando o conceito de vulnerabilidade e sua utilização em gestão para estratégias de prevenção. Trabalho apresentado no Seminário Tecnologias Grupais e Comunitárias de Prevenção, São Paulo, SP, Brasil.

Recebido: $18 / 06 / 2012$

$1^{a}$ revisão: 08/08/2012 Aceite final: 29/08/2012 